advanced countries may not be appropriate. The Rockefeller and McKnight Foundations have for many years supported crop biotechnology, capacity building, and technology transfer as part of a much broader set of strategies to help reduce poverty and hunger in developing countries. Constraints on IP associated with these programs led us to facilitate U.S. public-sector institutions in the establishment of the Public-Sector Intellectual Property Resource for Agriculture (PIPRA). Although we recognize that PIPRA cannot address all of the complex IP issues facing developing countries, we expect it to help, particularly with technology transfer and building IP capacity for more equitable partnerships. For example, PIPRA aims to develop educational tools for IP management, some targeted to the specific needs of developing countries. In addition, although PIPRA presently involves only public-sector institutions in the United States, if initially successful, participation may be broadened to involve similar institutions abroad, including those from the developing world.

It is true, as Huete-Pérez points out, that another major aim of PIPRA is to implement better public-sector management practices for IP relating to agricultural biotechnology to promote greater freedom to operate for improvement of specialty crops within the United States. However, the practice of licensing technologies to large corporations only for uses specifically needed by the corporations (for development of large-scale commercial crops) will also help ensure that these public-sector technologies will be available for use on crops important to the developing world. As foundations involved in support of agriculture in the developing world, we have experienced the difficulties faced in obtaining access to critical IP needed for projects involving biotechnology, and our support for PIPRA has been guided by the belief that it represents a promising new mechanism to help keep the results of publicsector research available for such efforts. Yet we agree with Huete-Pérez that there is a need for many other types of efforts to fully address the complex issues associated with the safe and appropriate use of new technologies to help poor people and communities in developing countries improve their livelihoods.

We also find much to agree with in the Letter by Korn and Heinig. In this regard, we note that our conversations and meetings with representatives from the institutions involved in PIPRA confirm that a major goal of this new initiative is indeed to do all possible to ensure that scientific discoveries and resulting technologies remain freely accessible to researchers. As mentioned in our Policy Forum, PIPRA participants aim to carefully weigh the option of disseminating discoveries via open publication versus the option of seeking patent protection. In the latter case, one of PIPRA's main goals is to promote the use of nonexclusive licensing or of limiting exclusive licenses to appropriately narrow fields of use. Such policies are very much in accordance with NIH guidelines.

GORDON CONWAY ${ }^{1}$ AND RIP RAPSON ${ }^{2}$

${ }^{1}$ The Rockefeller Foundation, 420 Fifth Avenue, New York, NY 10018-2702, USA. ${ }^{2}$ The McKnight Foundation, 710 Second Street South, Suite 400, Minneapolis, MN 55401, USA.

\section{Forgery: Prediction's Vile Twin}

AS EARLY AS 1830, CHARLES BABBAGE DISTINguished the following four kinds of scientific misconduct (1). Trimming is the smoothing of variation around the mean of a data set, in order to make it look extremely accurate. Cooking data is the omission of data sets (replicates) that do not fit one's expectations, or fudging around with constants in formulae until the results fit one's expectations (1). 


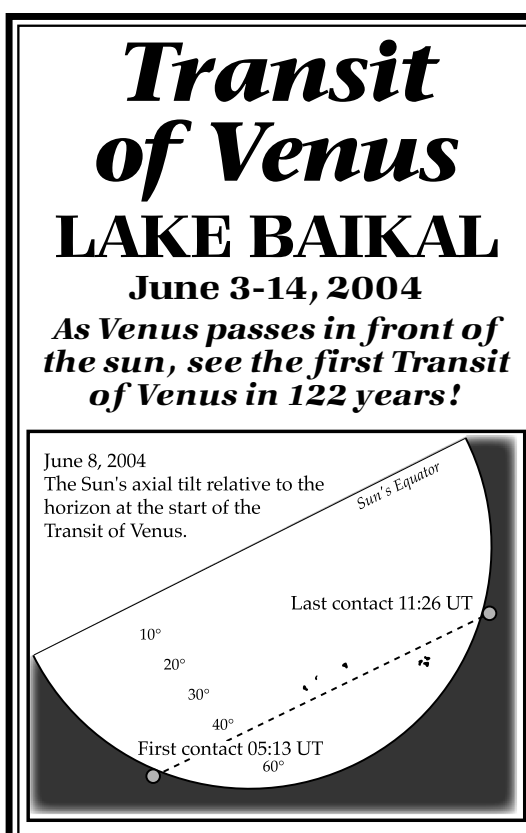

We invite you to join us for the extraordinary opportunity to see the Transit of Venus, June 3-14, $\mathbf{2 0 0 4}$, as we explore Siberia \& Lake Baikal :

Watch Venus slowly pass across the disk of the Sun! - an amazing phenomenon first predicted by Johann Kepler in 1631 and an inspiration for the great voyage of Captain Cook in 1769!

The last one occurred in 1882 so no one alive has seen one. Due to the nature of the motion of Venus, the Transits of Venus occur in twos and the next one will be in 2012 . After that there will be no others until 2117.

Our 12-day journey will begin in Moscow where we will discover the enchantment of Moscow's Kremlin and have a special visit to Star City, where Russia's cosmonauts and astronauts from many countries train.

We'll then fly to Irkutsk, the "Paris of Siberia," and go to the Lake Baikal Solar Observatory where we will observe the Transit of Venus! We will explore Lake Baikal for five days on board ship. The Russian "Galapagos Islands," Baikal is the single richest location in Russia for endemism. It is the oldest and deepest lake in the world.

Join us... as we discover the delights of Siberia and the Transit of Venus, which has fascinated astronomers for 372 years! \$3,295 + air.

\section{For a detailed brochure,} please call $(800) 252-4910$

\section{AAASTravels}

17050 Montebello Road

Cupertino, California 95014

Email:AAASinfo@betchartexpeditions.com

\section{LE T T E R S}

According to Babbage's definition, Mendel would have been an accomplished cook (2). Hoaxes are jokes usually played on "scientific academies, which have reached the period of dotage" (1). The goal of a hoax is the ridicule placed on those who credit it before it is disclosed. Finally, forging is the fabrication of fictitious results according to one's expectations, with the goals of gaining a reputation and never disclosing the forgery.

Babbage's growling account of Victorian science suggests that misconduct is a venerable phenomenon starting with Newton (3), rather than a young nuisance starting with Millikan (4). The roots of fraud should therefore be sought in basic tenets of science, rather than in modern funding or publishing policies (5). Here, I propose that misunderstanding the predictive power of science as a sort of guarantee to be right may be the primary motive for forgery.

The literature on scientific misconduct tells some of the most amusing, thrilling, distressing, maddening, and appalling stories of science [e.g., (5-8)]. All those who have written on scientific misconduct seem to agree that forgers usually do not want to falsify their research, but to cut corners in reaching a conclusion that they genuinely believe to be true [e.g., $(5,9)]$. This common theme among those who have studied the phenomenon of scientific misconduct, however, begs the question: How can forgers genuinely believe in the truth of their falsifications? Understanding the primary motives of perpetrators is the key to preventing scientific misconduct before it happens, which has been announced as a major goal by British and German science organizations (10).

Like men and women of genius, forgers often mistake their personal ideas, including their idiosyncrasies and subtle misunderstandings, as being exactly identical to abstracted scientific theories, and believe in their predic- tive power. Alas, technical journals, their editors, and reviewers obstinately insist on some kind of substantiation of any new idea, preferably experimental evidence. Why should the forgers go to the length of conducting the required experiments, when they can predict the outcome in advance, because they already know the proper theories?

Hence, forgery would be a homemade problem of scientists mistaking the predictive power of abstract things called science, or theory, with the predictive power of personal knowledge, or ideas. While the former might be considerable, the latter will always be very limited. The first step toward preventing more forgery should therefore lie in teaching a scepticism that suspects personal fallibility and selfdeception rather than deconstructing tenets like the predictive power and objectivity (11).

JOACHIM L. DAGG

Institute of Plant Pathology and Protection, Grisebachstrasse 6, 37077 Göttingen, Germany. E-mail: jdagg@gwdg.de

References

1. C. Babbage, in The Works of Charles Babbage, M. CampbellKelly, Ed. (Pickering, London, 1989), vol. 7, chap. 5.

2. Anonymous, Hort. Sci. 7, 5 (1972).

3. R. S. Westfall, Science 179, 751 (1973).

4. G. Holton, Hist. Stud. Physical Sci. 9, 166 (1978).

5. W. Broad, N. Wade, Betrayers of the Truth (Oxford Univ. Press, Oxford, 1985), chap. 2.

6. K. Sabbagh, A Rum Affair: A True Story of Botanical Fraud (Da Capo, New York, 2001).

7. J. Crewdson, Science Fictions: A Scientific Mystery, a (Little Brown, Boston, 2002).

8. D. Kennedy, Science 300, 393 (2003).

9. A. Abbott, Nature 398, 13 (1999).

10. M. Hagmann, Science 286, 2258 (1999).

11. R. S. Berry, Science 300, 134 (2003).

\section{CORRECTIONS AND CLARIFICATIONS}

News Focus: "A healthful dab of radiation?" by J. Kaiser (17 Oct., p. 378). Sheldon Wolff did not win a Nobel prize. Also, a recent analysis challenges earlier claims that atomic bomb survivors exposed to low radiation doses are living longer than controls: www.rerf.or.jp/eigo/update/spring2002.pdf. Massive Coverup, and the Dark Legacy of Robert Gallo

\section{TECHNICAL COMMENT ABSTRACTS \\ COMMENT ON "Salt-Pump Mechanism for Contaminant Intrusion into Coastal Aquifers"}

\section{R. Lloyd}

Dror et al. (Brevia, 9 May 2003, p. 950) claimed a dramatic effect for diffusion of contaminants out of salt water. However, the results reported cannot be due to simple diffusion, and the proposed activity-driven mechanism is not consistent with the observations. This casts doubt on the suggested contaminant intrusion. Possible explanations of the observations are suggested.

Full text at www.sciencemag.org/cgi/content/full/302/5646/784b

\section{ReSPONSE TO COMMENT ON "Salt-Pump Mechanism for Contaminant Intrusion into Coastal Aquifers"}

\section{Ishai Dror, Bruno Yaron, Brian Berkowitz}

Our study demonstrated high organic compound $(\mathrm{OC})$ concentrations in saltwater and significantly enhanced transport to freshwater. Transport of OCs is not a purely molecular diffusive process. Contrary to the Comment by Lloyd, we argue that the "salt pump mechanism" is also clearly influenced by saltwater-freshwater density differences. New supporting experimental results are presented.

Full text at www.sciencemag.org/cgi/content/full/302/5646/784c 